\title{
Tail autotomy effects on the escape behavior of the lizard Gonatodes albogularis (Squamata: Sphaerodactylidae), from Córdoba, Colombia
}

\author{
Moisés E Domínguez-López ${ }^{1 *}$, Ángela M Ortega-león and Gastón J Zamora-abrego ${ }^{3}$
}

\begin{abstract}
Background: Caudal autotomy appears to be an adaptation strategy to reduce the risk of being preyed upon. In an encounter with a predator, the prey must reduce the risk of being preyed upon, and one of the strategies that has exerted a strong pressure on selection has been tail loss. In lizards, it has been demonstrated that tail loss reduces the probability of survival in the event of a second attack; therefore, they must resort to new escape strategies to reduce the risk of falling prey. In order to evaluate the effect of tail loss on the escape behavior of Gonatodes albogularis in natural conditions, we took samples from a forest interior population. We expected that individuals that had not lost their tails would allow the predator to get closer than those that had lost it. For each sample, we recorded the following: (1) escape behavior, measured through three distances (e.g., approach distance, escape distance, and final distance); (2) distance to shelter; and (3) length of tail. We included only males in the study since we did not record any females without a tail and far fewer with a regenerated tail.

Results: We found that tail loss does have an effect on the escape behavior of G. albogularis. Males that have their tails intact allow the predator to come closer, and we found a negative correlation between the approach distance and the length of the tail.
\end{abstract}

Conclusion: Our results support the escape behavior theory, in which G. albogularis males drop their tails when the risk of predation is much higher than the cost of fleeing.

Keywords: Caudal autotomy; Escape behavior; Predation; G. albogularis

\section{Background}

In lizards, caudal autotomy is considered an anti-predation strategy, the main aim of which is to increase survival of the individual when other escape behavior has been ineffective (Maginnis 2006; Bateman and Fleming 2009; Lovely et al. 2010). However, tail loss has associated costs during the regeneration period in terms of reproduction and survival (Shine 1980; Fox and McCoy 2000; Webb 2006). For example, the absence of the tail in the first instance affects balance and all processes associated with locomotive performance (Vitt and Ohmart 1975; Ballinger et al. 1979; Arnold 1988; Martín and Avery, 1998), stockpiling resources (Vitt et al. 1977; McConnachie and Whiting 2003; Clause and Capaldi 2006), and social status (Martin

\footnotetext{
* Correspondence: moises.gdom@yahoo.com.co

'sección Herpetología, departamento de vertebrados, Museo de la Plata,

Paseo del bosque s/n, la Plata, 1900 Buenos Aires, Argentina

Full list of author information is available at the end of the article
}

and Salvador 1993; Salvador et al. 1995; Niewiarowski et al. 1997; Fox and McCoy 2000). In addition, caudal autonomy makes individuals more vulnerable to predation (Dial and Fitzpatrick 1984; Daniels et al. 1986; Downes and Shine 2001; Cooper et al. 2004; Medger et al. 2008). In addition, tail regeneration requires a large amount of energy, and individuals must undergo periods of nutritional deficiency, such that adults stop reproducing, while younger groups stop growing while the tail regenerates (Arnold 1988; Andersson 1994; Webb 2006; Doughty et al. 2003; Lin et al. 2006).

In tree-dwelling lizards, running and jumping are the locomotive methods most commonly employed for moving through the habitat, capturing prey, and evading predation (Moermond 1979; Pounds 1988; Losos and Irschick 1996; Irschick and Losos 1998). However, few studies on caudal autotomy have examined the costs of tail loss with regard to escape behavior, since the tail is 
used for gripping the substrate or for propelling the body during movement as well as for speed and resilience (Toro et al. 2003, 2004; Lailvaux and Irschick 2007; Fleming and Bateman 2011). In the Anolis genus of lizard, patterns of movement and the position of the tail can affect its ability to jump and consequently its escape agility (Higham et al. 2001; Gillis et al. 2009). In some species of geckos, it has been demonstrated that the tail determines the direction of the body when moving from one place to another, which helps it to avoid predation (Jusufi et al. 2008; Sun et al. 2009; Ding et al. 2012). Thus, lizards develop early escape behaviors in order to minimize the negative consequences of caudal autotomy (Cooper 2003, 2007), as well as implementing search behaviors for anti-predation shelters (Formanowicz et al. 1990; Langkilde et al. 2005; Zhao et al. 2008). Ultimately, however, any post-caudal autotomy behavior potentially reduces the individual's adaptation capacity (Maginnis 2006; Gillis et al. 2009; Fleming and Bateman 2011).

Within this context, we used the Gonatodes albogularis lizard as a model, and we examined the effects that caudal autotomy has on escape behavior. Specifically, we concentrated on answering the following questions: (i) Are there significant differences in the approach distances of a potential predator between individuals with their tails intact and those without tails or with partially regenerated tails?; (ii) Does the length of the tail have a significant relationship with the approach distance, the final distance, and the escape distance?; and (iii) Are there significant differences in the shelter distances between individuals with their tails intact and those without tails or with partially regenerated tails? For this exercise, we concentrated on males, since no females with caudal autotomy were found while the study was being carried out.

\section{Methods \\ Study area}

Fieldwork was conducted in a tropical dry forest relict (Tr-DF) to the south of the Department of Córdoba, Columbia. The study site is located at a height of $12 \mathrm{~m}$ above see level, between $08^{\circ} 34^{\prime} 48.7^{\prime \prime} \mathrm{N}$ and $75^{\circ} 42^{\prime} 28.4^{\prime \prime} \mathrm{W}$. The median annual temperature is $28^{\circ} \mathrm{C}$ with $1,300 \mathrm{~mm}$ of annual rainfall distributed in a unimodal-biseasonal pattern (e.g., dry season and rainy season). Notably, the study site belongs to one of the last wooded outposts in the Department of Córdoba and in the Caribbean region, in the biogeographical province of Choco-Magdalena (Hernández-Camacho et al. 1992).

\section{Study model}

The yellow-headed gecko Gonatodes albogularis (Duméril \& Bibron, 1836) is a relatively small (up to $51.0 \mathrm{~mm}$ in rostrum-cloacal length), diurnal, tree-dwelling lizard of the Sphaerodactylidae family, and native to the lowlands of Chiapas, México on the Pacific watershed and Guatemala on the Atlantic watershed, extending to the south down to the northwest of Columbia and western Venezuela (Savage 2002) and also found on islands such as Aruba, Curacao, Tortuga, La Orchila, Gorgona, La Española, Jamaica, The Cayman Islands, and Cuba (Krysko 2005). It lives in dry and wet tropical forests, both in primary and secondary forests, and in open areas, from sea level up to a maximum altitude of 1,500 m (Rivero-Blanco 1979; Köhler 2003; Schargel 2008). They are generally found in proximity to tree trunks, but they can also be observed in cracks in rocks and rarely on fallen leaves. They present with marked sexual dimorphism: male adults have a black body, a whitish stomach, an orange-colored or dark yellow head, a black retina, and white distal end of the tail; while females present with a coffee-colored base upon which there are many light spots, from white to cream, across the whole body, but without the white tail tip. They do not have movable eyelids; the body and the head are covered with granular scales, and the fingers are cylindrical with non-retractable claws (Ellingson 1994). The natural predators of this species are larger lizards and some species of snakes, birds, and mammals (Fitch 1973; Bello 2000).

\section{Fieldwork}

The samples were taken between March and April of 2012. During sample collection, we used the free search method without restrictions between 0900 and 1700 hours. For the escape behaviors, a potential predator was simulated by a person, always the same individual, who always approached at a constant speed $\left(1 \mathrm{~m} \mathrm{~s}^{-1}\right)$. Once each individual was located, we recorded the first reaction that it demonstrated (e.g., movement of the head, of the tail, or any other reaction) as an indication that the 'prey' had detected the 'predator'. The escape behavior was measured in the following way: (i) the 'predator' placed himself at a distance of $5.0 \mathrm{~m}$ and began the approach towards each individual directly and in a straight line, at a constant speed; (ii) once the lizard began its escape behavior, the 'predator' stopped. Immediately afterwards, the approach distance, the escape distance, and the final distance were measured. All distances were taken in a straight line using a tape measure. The approach distance was defined as the distance between the 'predator' and the lizard at the moment in which the latter began its escape. The escape distance was the distance between the lizard's initial resting place and the point at which it stopped after its escape; and the final distance was the distance between the 'predator' and the point at which the lizard stopped after its escape (Bauwens and Thoen 1981; Bulova 1994; Vanhooydonck et al. 2007). If the lizard ran and hid (e.g., in a crack and underneath fallen leaves), the 
escape distance was measured between the initial position of the individual and the entrance to the hiding place. To reduce the possibility of repeatedly observing the same individual, the excursions were made on parallel transects that were marked and separated from each other by $10 \mathrm{~m}$.

In addition to these distances, the distance to the nearest place of shelter was also measured. This was the distance between the initial position of the individual and the place that it disappeared from view (e.g., crack, hollow, and tree bark).

Once the observations had been taken, all of the individuals were captured and measured (rostrum-cloacal length (RCL); tail length (TL)) with an analog Vernier caliper (precision $0.1 \mathrm{~mm}$ ). The state of the tail was also recorded (e.g., tail intact, missing tail, and with regenerated tail). Only those individuals with a RCL higher than the minimum for sexual maturity $(30.1 \mathrm{~mm}$ for males and 31.7 for females; Serrano-Cardozo et al. 2007) were included in the sample.

\section{Statistical analysis}

All of the variables were transformed $(\log 10)$ before carrying out the analysis. In order to see whether escape behavior differs depending on the state of the tail, a multivariate analysis of variance (MANOVA) and an analysis of variance (ANOVA) were applied using STATISTICA 2001 Version 8.0, with the state of the tail as a factor and the approach distance, escape distance, final distance, and the distance to shelter as dependent variables. Subsequently, with a post hoc analysis (Tukey), we identified which comparisons accounted for significant differences (Dytham 1999). Finally, we used a Pearson correlation to examine if there was any relationship between tail size and escape behavior.

\section{Results}

We recorded a total of 79 male adults and found individuals with tails in different states (e.g., intact, absent, and regenerated). We found that tail loss does have an effect on escape behavior. The multivariate analysis of variance allowed us to observe that the state of the tail has an effect on escape behavior $\left(F_{2,76}=67.765, P=0.0001\right)$. The analysis of variance showed that the approach distance differed significantly between tail states $\left(F_{2,76}=52.898, P=0.00001\right.$; Figure 1). However, with regard to the escape distance and the final difference there, were no significant differences $\left(F_{2,76}=2.5680, \quad P=0.08333 ; \quad F_{2,76}=0.36929, \quad P=0.69246\right.$; Figure 2 and 3, respectively). Tukey's post hoc analysis revealed differences in the approach distance between individuals with an intact tail and the other groups (e.g., absent tail and regenerated tail; Table 1).

We also observed that individuals with tails in different states of regeneration were found in different places

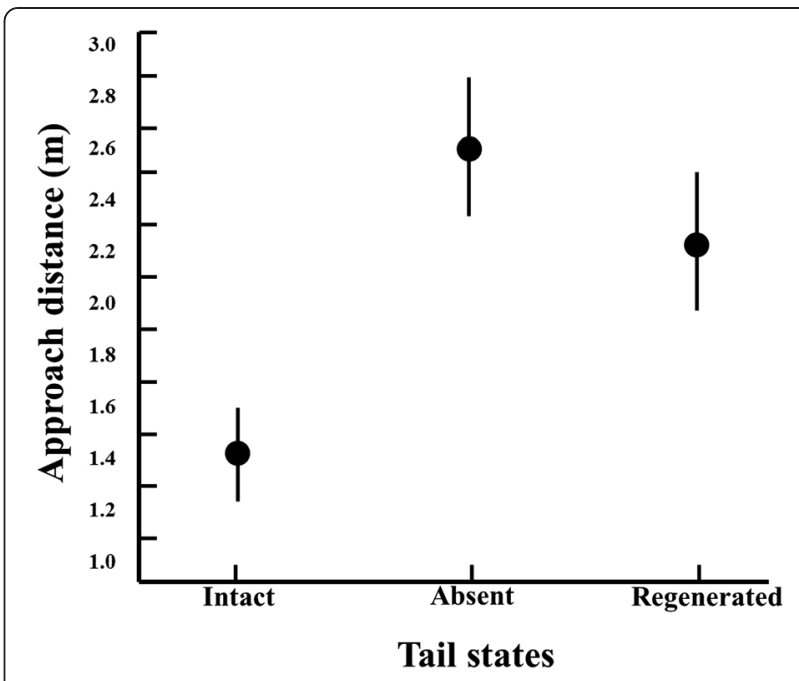

Figure 1 Approach distance vs. tail states. Approach distance $(m)$ that male Gonatodes albogularis exhibit when confronted with a potential predator in relation to three tail states (average $\pm \mathrm{IC}$ ).

within the microhabitat with regard to the closeness to, or distance from, places of safety. The analysis of variance showed differences in the distance to shelter between individuals with different tail states $\left(F_{2,76}=12.956\right.$, $P=0.00001$; Figure 4). The post hoc analysis revealed differences between individuals with an intact tail and the other groups (e.g., absent tail and regenerated tail; Table 1).

Tail length seems to be related to escape behavior to a large degree. The correlation analysis showed that there is a significant negative correlation between the approach distance and the length of the tail $(r=-0.71, P>0.05$; Figure 5). In other words, when individuals have a longer tail, they allow the predator to come closer, while escape

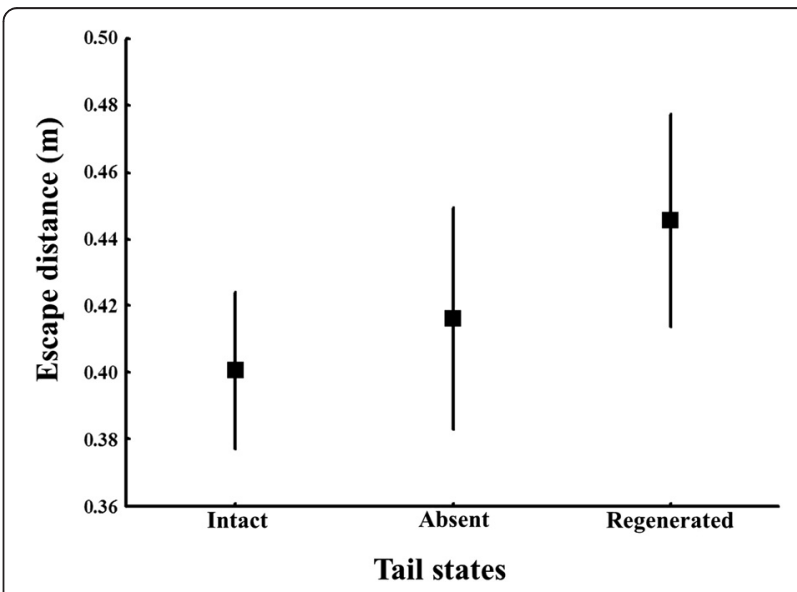

Figure 2 Escape distance vs. tail states. Escape distance $(m)$ that male Gonatodes albogularis exhibit when confronted with a potential predator in relation to three tail states (average \pm IC). 
Table 1 Tukey's a posteriori analysis

\begin{tabular}{lll}
\hline Tail & Intact & Absent \\
\hline Intact & & \\
Absent & $0.000109 ; 0.000119$ & \\
Regenerated & $0.000109 ; 0.024502$ & $0.265345 ; 0.094200$ \\
\hline
\end{tabular}

This analysis shows the comparisons between individuals with intact, absent, or regenerated tail regarding approach distance (first values) and refuge distance (second values).

distances and final distances were not related to tail length $(r=-0.15, P>0.05 ; r=-0.08, P>0.05$, respectively).

\section{Discussion}

Our results demonstrate that tail loss does have an effect on the escape behavior of the lizard G. albogularis. The individuals we found with different tail states (e.g., intact, absent, and regenerated) were males only. This pattern could be explained by various factors: it is possible that it is much more costly for females to lose their tails, since they would expend a great deal of energy during the time that it is regenerating, energy that could be used for other activities. G. albogularis females have a continuous reproductive cycle, which indicates that they are always investing energy in the production of ovules (Serrano-Cardozo et al. 2007). Therefore, regenerating their tails would imply an additional energy expenditure. Bohórquez et al. (2010) found that this lizard uses a tailwaving display in the presence of conspecifics and potential predators and that males use this type of behavior with a significantly higher frequency than females, finding that the differences were significant.

It is known that ovule production implies greater energy expenditure than the production of spermatozoids (Krebs and Davies 1993; Andersson 1994), and this

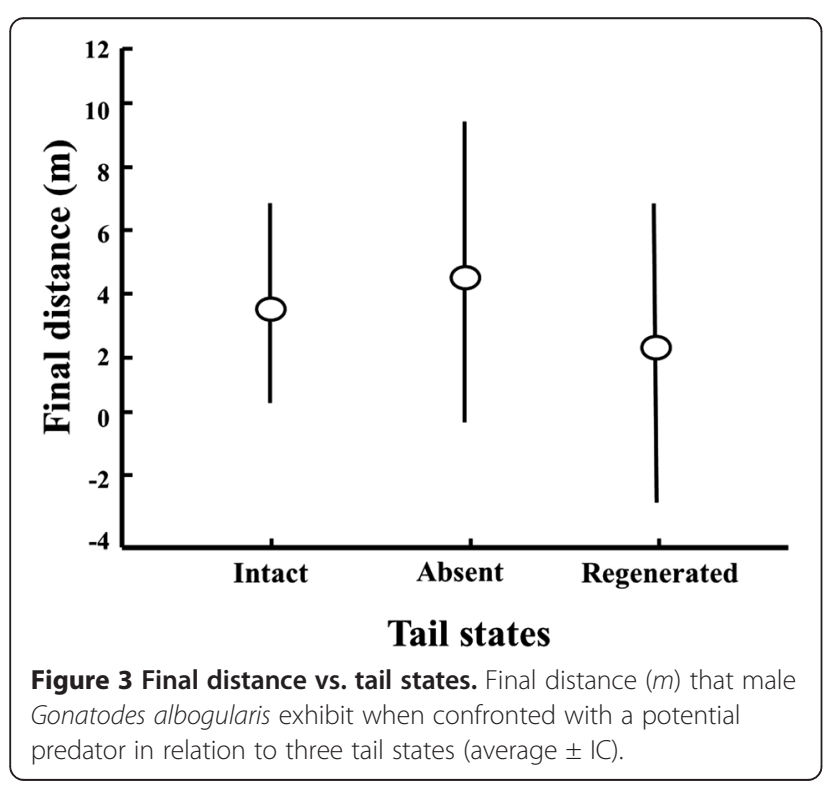

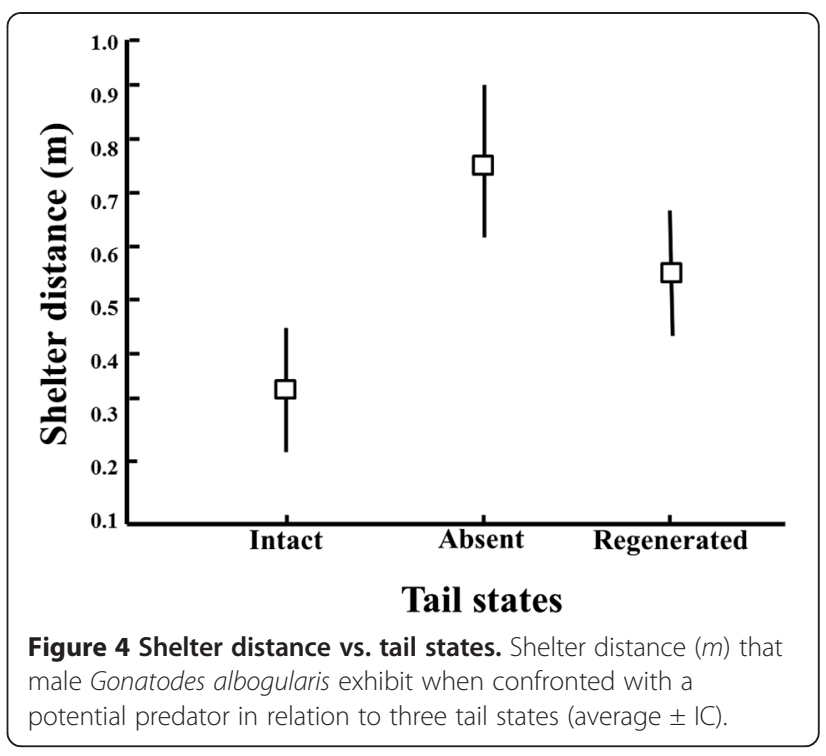

applies equally to reptiles (Congdon et al. 1982). In addition, it is the females of this species of lizard that take care of the nest (MD-L, personal observation), which is to say that they have an additional expenditure compared with males. For all of the above reasons, it is much easier for males to drop their tails, and this is why they use the tail-waving display more frequently. If a predator seizes them by the tail, they drop it and can successfully evade a predatory event. Females cannot take such risks since they must distribute their energy to other activities such as ovule production and parental care, which is undertaken by the females in this species of lizard (MD-L, personal observation). Besides this, it is very possible that females do not need to carry out this kind of behavior since they are much more reticent and reclusive than males (Ellingson 1994).

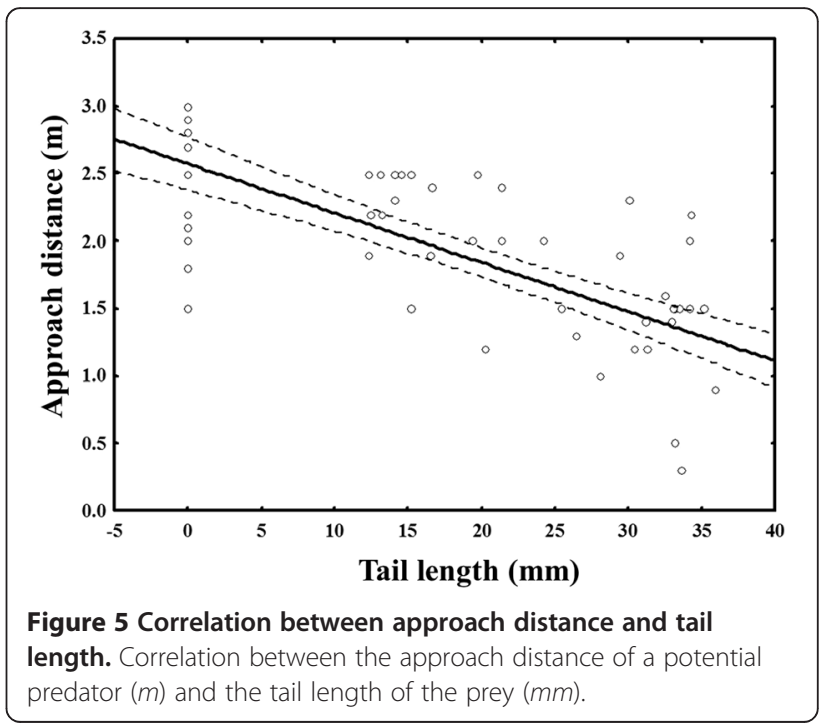


It has been demonstrated that tail loss brings about a loss of running speed, which could constitute a significant disadvantage for lizards (Ballinger et al. 1979; Punzo 1982; Dial and Fitzpatrick 1984), thus increasing the risk of predation. It has been suggested therefore that the reduction in the distance that the prey allow to the predator, after the loss of the tail, as has been seen in some ground lizards, could be combined with a change in strategy for avoiding predators. Becoming more reticent or keeping to habitats with larger objects for protection is one example of a change in strategy (Formanowicz et al. 1990; Smith 1996).

Our results reflect the fact that the approach distances were smaller in males with intact tails, indicating that individuals that have the opportunity to execute caudal autotomy allow the predator to come closer. This affirms the escape behaviors theory put forward by Ydenberg and Dill (1976), in which an animal decides to escape when the risk of predation is greater than the cost of escape; ultimately, G. albogularis males drop their tails, since it is otherwise much more likely that they would fall prey.

Our data do not show if caudal autotomy has an influence on the probability that the lizard G. albogularis would survive an encounter with potential predators (e.g., snakes, birds, and mammals; Fitch 1973; Bello 2000). However, we have demonstrated that tail loss modifies escape behavior and has direct repercussions on encounters with a potential predator, which increases the possibility that these lizards are preyed upon more easily. In addition, tail loss also induces changes in behavior that are not directly related to predation, and these modifications can indirectly affect the probability that a lizard will be captured (Fox and Rostker 1982; Martin and Salvador 1993, 1997).

We found a strong negative correlation between the approach distance and the length of the tail. In other words, when individuals have a longer tail, they allow the predator to come closer. It has been demonstrated that the tail is used to maintain balance during movement in ground habitats (Vitt and Ohmart 1975; Ballinger et al. 1979), and it has also been demonstrated that G. albogularis uses some movements that are known as tail-waving display, which act as a behavior to evade and dissuade predators (Bohorquez et al. 2010). We believe that when individuals have a longer tail, they are more agile and allow the predator to come closer. In addition, we can say that when the tail is longer, the tail-waving display is much more effective and dissuades predators more easily.

With regard to the use of space, we found that individuals with intact tails tend to be found in areas close to shelter, while individuals with absent tales move much further away from shelter. This scenario suggests that while tail loss reduces locomotive abilities in some lizards (Ballinger et al. 1979), it increases them in others (Daniels 1983). Therefore, it is probable that tail loss does not decrease running speed in this species of lizard. However, this may contradict the negative correlation between the approach distance and tail length, since the length of the tail would be more associated with evasion and dissuasion (tail-waving display) than with running distance.

\section{Conclusions}

Individuals who have lost the tail become more vulnerable to predation, is why you should take the race long before individuals with tail intact, G. albogularis not only uses its tail to detach, but has developed a deterrence strategy and evasion which also uses the queue. So by not having it is more exposed to predation.

There may be an effect on many variables set on escape behavior in the lizard G albogularis, however caudal autotomy seems to be a strategy that allows individuals successfully overcome a meeting with a potential predator.

\section{Competing interests}

The authors declare that they have no competing interests.

\section{Authors' contributions}

MD-L Participated in all article; AO- $L$ participated in the design of the study and performed the statistical analysis and JZ-O participated in the discussion and conclusions.

\section{Acknowledgements}

We would like to give our thanks to the two anonymous editors of this text. To Daniel Ochoa for all the support provided at the study site and to the Variation in behavioral and demographic aspects of common amphibious species and reptiles in forest fragments and urban areas in the Department of Córdoba' project.

\section{Author details}

'sección Herpetología, departamento de vertebrados, Museo de la Plata, Paseo del bosque s/n, la Plata, 1900 Buenos Aires, Argentina. ${ }^{2}$ Grupo de Investigación en Biodiversidad, Universidad de Córdoba, Carrera 6 No. 76-103, Córdoba 14071, Colombia. ${ }^{3}$ Departamento de Ciencias Forestales, Facultad de Ciencias Agrarias, Universidad Nacional de Colombia, Medellín, Antioquia C.P. 050034, Colombia.

Received: 26 August 2013 Accepted: 23 June 2014

Published online: 07 January 2015

\section{References}

Andersson M (1994) Sexual selection. Princeton University Press, Princeton, pp 1-599 Arnold E (1988) Caudal autotomy as a defense. In: Gans C, Huey RB (eds) Biology of the Reptilia, vol 16. Alan R, Liss, New York, pp 235-273

Ballinger RE, Noetfeldt JW, Krupa JJ (1979) An experimental analysis of the role of the tail in attaining high speed in Cnemidophorus sexlineatus (Reptilia: Squamata: Lacertilia). Herpetologica 35:114-116

Bateman PW, Fleming PA (2009) To cut a long tail short: a review of lizard caudal autotomy studies carried out over the last 20 years. J Zool 277:1-14

Bateman PW, Fleming PA (2011) "Frequency of tail loss reflects variation in predation levels, predator efficiency, and the behaviour of three populations of brown anoles". Biological Journal of the Linnean Society 103:648-656

Bauwens D, Thoen C (1981) Escape tactics and vulnerability to predation associated with reproduction in the lizard Lacerta vivipara. J Anim Ecol $50: 733-743$

Bello R (2000) Anolis sp and Gonatodes albogularis (yellow-headed gecko) predation. Herpetol Rev 31:239-240 
Bohórquez M, Martínez J, Aguilar A, Font E, Molina-Borja M (2010) Sex differences in antipredator tail-waving displays of the diurnal yellow-headed gecko Gonatodes albogularis from tropical forests of Colombia. J Ethol 28:305-311

Bulova J (1994) Ecological correlates of population and individual variation in antipredator behavior of two species of desert lizards. Copeia 4:980-992

Clause AR, Capaldi EA (2006) Caudal autotomy and regeneration in lizards. J Exp Zool 305:965-973

Congdon JD, Dunham AE, Tinkle DW (1982) Energy budgets and life history of reptiles. In: Gans C, Pough HF (eds) Biology of the Reptilia, vol 13. Academic, London, pp 233-271

Cooper WE Jr (2003) Shifted balance of risk and cost after autotomy affects use of cover, escape, activity, and foraging in the keeled earless lizard (Holbrookia propinqua). Behav Ecol Sociobiol 54:179-187

Cooper WE Jr (2007) Compensatory changes in escape and refuge use following autotomy in the lizard Sceloporus virgatus. Can J Zool 85:99-107

Cooper WE Jr, Pérez-Mellado V, Vitt $\sqcup J$ (2004) Ease and effectiveness of costly autotomy vary with predation intensity among lizard populations. J Zool 262:243-255

Daniels C (1983) Running: an escape strategy enhanced by autotomy. Herpetologica 12:162-165

Daniels C, Flaherty S, Simbotwe M (1986) Tail size and effectiveness of autotomy in a lizard. J Herpetol 20:93-96

Dial B, Fitzpatrick L (1984) Predator escape success in tailed versus tailless Scincella lateralis (Sauria: Scincidae). Anim Behav 12:301-302

Ding G, Fu T, Zhou Z, Ji X (2012) Tail autotomy does not increase locomotor costs in the oriental leaf-toed gecko Hemidactylus bowringii. Asian Herpetological Res 3:141-146

Doughty P, Shine R, Lee M (2003) Energetic costs of tail loss in a montane scincid lizard. Comp Biochem Physiol 135:215-219

Downes S, Shine R (2001) Safety or solitude? Using habitat selection experiments to identify a lizard's priorities. Animal Behavior 55:1387-1396

Dytham C (1999) Choosing and using statistics. Blackwell Science, London

Ellingson J (1994) Natural and sexual selection on coloration in the diurnal gecko Gonatodes albogularis, Ph.D. thesis. University of Texas at Austin, Austin

Fitch HS (1973) A field study of Costa Rican lizards. Univ Kans Sci Bull 50:39-126

Formanowicz D Jr, Brodie E Jr, Bradley P (1990) Behavioural compensation for tail loss in the ground skink, Scincella lateralis. Animal Behavior 40:782-784

Fox SF, McCoy KJ (2000) The effects of tail loss on survival, growth, reproduction, and sex ratio of offspring in the lizard Uta stansburiana. Oecologia 122:327-34

Fox S, Rostker M (1982) Social costs of tail loss in Uta stansburiana. Science 218:692-693

Gillis GB, Bonvini LA, Irschick DJ (2009) Losing stability: tail loss and jumping in the arboreal lizard Anolis carolinensis. J Exp Biol 212:604-609

Hernández-Camacho J, Hurtado A, Ortiz R, Walschburger T (1992) Unidades biogeográficas de Colombia. In: La diversidad biológica de Iberoamérica. Edited by Halffter G.: Acta Zoológica Mexicana, México, pp 105-151

Higham TE, Davenport MS, Jayne BC (2001) Maneuvering in an arboreal habitat: the effects of turning angle on the locomotion of three sympatric ecomorphs of Anolis lizards. J Exp Biol 204:4141-4155

Irschick DJ, Losos JB (1998) A comparative analysis of the ecological significance of locomotor performance in Caribbean Anolis lizards. Evolution 52:219-226

Jusufi A, Goldman D, Revzen S, Full RJ (2008) Active tails enhance arboreal acrobatics in geckos. National Acad Sci 105:4215-4219

Köhler G (2003) Reptiles of Central America. Herpeton, Offenbach, p 367

Krebs J, Davies N (1993) Sexual conflict and sexual selection. In: Krebs J and Davies N (eds) An introduction to behavioral ecology. Blackwell, Oxford, $420 \mathrm{p}$

Krysko KL (2005) Ecological status of the introduced yellow headed gecko, Gonatodes albogularis (Sauria: Gekkonidae), in Florida. Florida Scientist Biol Sci $68: 272-280$

Lailvaux S, Irschick DJ (2007) Effects of temperature and sex on jump biomechanics and performance in the lizard Anolis carolinensis. Funct Ecol 21:534-543

Langkilde T, Alford RA, Schwarzkopf L (2005) No behavioural compensation for fitness costs of autotomy in a lizard. Austral Ecology 30:713-718

Lin ZH, Qu YF, Ji X (2006) Energetic and locomotor costs of tail loss in the Chinese skink, Eumeces chinensis. Comp Biochem Physiol 143:508-513

Losos JB, Irschick DJ (1996) The effect of perch diameter on escape behaviour of Anolis lizards: laboratory predictions and field tests. Anim Behav 51:593-602

Lovely K, Luke D, Revell L (2010) The rate and pattern of tail autotomy in five species of Puerto Rican anoles. Evol Ecol Res 12:67-88

Maginnis TL (2006) The costs of autotomy and regeneration in animals: a review and framework for future research. Behav Ecol 17:857-872
Martín J, Avery R (1998) Effects of tail loss on the movement patterns of the lizard, Psammodromus algirus. Funct Ecol 12:794-802

Martin J, Salvador A (1993) Tail loss reduces mating success in the Iberian rock lizard, Lacerta monticola. Behav Ecol Sociobiol 32:185-9

Martin J, Salvador A (1997) Effects of tail loss on the time-budgets, movements, and spacing patterns of Iberian rock lizards, Lacerta monticola. Herpetologica $53: 117-125$

McConnachie S, Whiting M (2003) Costs associated with tail autotomy in an ambush foraging lizard, Cordylus melanotus melanotus. Afr Zool 38:57-65

Medger K, Verburgt L, Bateman PW (2008) The influence of tail autotomy on the escape response of the Cape dwarf gecko, Lygodactylus capensis. Ethology 114:42-52

Moermond TC (1979) Habitat constraints on the behavior, morphology, and community structure of Anolis lizards. Ecology 60:152-164

Niewiarowski PH, Congdon JD, Dunham AE, Vitt LJ, Tinkle DW (1997) Tales of lizard tails: effects of tail autotomy on subsequent survival and growth of free-ranging hatchling Uta stansburiana. Can J Zool 75:542-8

Pounds JA (1988) Ecomorphology, locomotion, and microhabitat structure: patterns in a tropical mainland Anolis community. Ecol Monogr 58:299-320

Punzo C (1982) Tail autotomy and running speed in the lizards Cophosaurus texanus and Uma notata. J Herpetol 12:331-332

Rivero-Blanco C (1979) The neotropical lizard genus Gonatodes Fitzinger (Sauria: Spherodactylinae), Ph.D. thesis. Texas A\&M University, College Station

Salvador A, Martín J, López P (1995) Tail loss reduces home range size and access to females in male lizards, Psammodromus algirus. Behav Ecol 6:382-387

Savage JM (2002) The amphibians and reptiles of Costa Rica: A Herpetofauna Between Two Continents, Between Two Seas. University of Chicago Press, Chicago

Schargel W (2008) Species limits and phylogenetic systematic of the diurnal geckos of the genus Gonatodes (Squamata: Sphaerodactylidae). Ph.D. dissertation. The University of Texas at Arlington, Arlington

Serrano-Cardozo V, Ramírez-Pinilla M, Ortega J, Cortés L (2007) Annual reproductive activity of Gonatodes albogularis (Squamata: Gekkonidae) living in an anthropic area in Santander, Colombia. South Am J Herpetol 2:31-38

Shine R (1980) "Costs" of reproduction in reptiles. Oecologia 46:92-100

Smith GR (1996) Correlates of approach distance in the striped plateau lizard (Sceloporus virgatus). Herpetol J 6:56-58

Sun Y, Yang J, Ji X (2009) Many-lined sun skinks (Mabuya multifasciata) do not compensate for the costs of tail loss by increasing feeding rate or digestive efficiency. J Exp Zool A 311:125-133

Toro E, Herrel A, Vanhooydonck B, Irschick DJ (2003) A biomechanical analysis of intra- and interspecific scaling of jumping and morphology in Caribbean Anolis lizards. J Exp Biol 206:2641-2652

Toro E, Herrel A, Irschick DJ (2004) The evolution of jumping performance in Caribbean Anolis lizards: solutions to biomechanical trade-offs. Am Nat 163:844-856

Vanhooydonck B, Herrel A, Irschick D (2007) Determinants of sexual differences in escape behavior in lizards of the genus Anolis: a comparative approach. Integr Comp Biol 47:200-210

Vitt L, Ohmart R (1975) Ecology, reproduction, and reproductive effort of the iguanid lizard Urosaurus graciosus on the Lower Colorado River. Herpetologica 3:156-65

Vitt L, Congdon JD, Dickson NA (1977) Adaptive strategies and energetics of tail autotomy in lizards. Ecology 58:326-337

Webb JK (2006) Effects of tail autotomy on survival, growth and territory occupation in free-ranging juvenile geckos (Oedura lesueurii). Austral Ecol $31: 432-440$

Ydenberg R, Dill $L$ (1986) The economics of fleeing from predators. Adv Stud Behav 16:229-249

Zhao Q, Wang Z, Liu LL, Zhao WG, Ji X (2008) Selected body temperature, surface activity and food intake in tailed versus tailless Mongolian racerunners Eremias argus from three populations. Acta Zoologica Sinica 54:60-66 